\title{
Making Instant Adjustments in Online Journalism Education: Responding to Continuous Needs Assessments in Asynchronous Courses
}

\author{
Amanda C. Bright \\ University of Georgia
}

\begin{abstract}
The creation of an effective learning environment is always a challenge, but when the environment is online and the learners are a diverse group of adults in a specialized content area, the challenges become more complex. This best practices study used the intersection of the importance of the learner, Knowles's andragogy concepts, and the Dick and Carey instructional design model to make continuous needs assessment the cornerstone of three, graduate-level online courses during a single summer session. Through the use of recursive needs assessment, the instructor was able to provide a personal and practical level of instruction in the asynchronous courses that ultimately benefited the students.
\end{abstract}

Keywords: online learning, andragogy, needs assessment, instructional design, asynchronous, differentiated instruction

Bright, A.C. (2020). Making instant adjustments to online journalism education: Responding to continuous needs assessments in asynchronous courses. Online Learning, 24(2), 245-253. https://doi.org/10.24059/olj.v24i2.2034

\section{Making Instant Adjustments in Online Journalism Education: Responding to Continuous Needs Assessments in Asynchronous Courses}

Truly differentiated instruction-where learning meets each student's unique needs - is one of an educator's greatest desires, and it has transitioned in rhetoric from preferable to principle at all levels of learning. According to Murray (2017), student needs have become paramount at learning institutions, where instructors often employ technological tools in order to design instruction specifically for individual learners.

Although we know education that is responsive to each student is part of best practice, the method for making it both possible and viable can be elusive. How can a single instructor meet individual learners where they are at, set individual learning outcomes for each person, and 
see each of those goals come to fruition by the end of a single semester? This notion is particularly constrained when the learners are college-level adults coming from sometimes remarkably disparate levels of knowledge and ability. It is even more complex when the course delivery is online, which means transformed options for student engagement and the ability to understand what each learner needs to thrive. Sometimes, technology drives this part of the conversation, but according to a thirty-year analysis of online learning theories by Mayer (2019), a recurring theme to address this complexity should be "instructional methods rather than instructional media" (p. 152).

In a face-to-face learning setting where so many needs and wants are competing within a certain timeframe, to meet each student where he or she is at can be to derail or deviate in a way that compromises other learners. Yet in online education, and particularly with adult learners who have a clear sense of their own capabilities and desires, there is a real opportunity for implementing instructional methods that are highly responsive and individualized-most notably through an enhanced focus on continual and recursive needs assessment in a way that we have only begun to fully exploit in distance education.

\section{Review of Relevant Literature}

Meeting students' needs so they can learn at their highest potential is the crux of the challenge in education - whether inside a physical classroom or not. Abrami, Bernard, Bures, Borokhovski, \& Tamim (2011), in an extensive meta-analysis, identified self-regulation, motivation and collaboration as needed areas in learning, particularly in online environments. In a comprehensive study in 2012, three researchers who studied online learning in higher education in the southeast of the U.S. found that a number of factors complicate good pedagogy when learning at a distance. Limited resources in funding and technology, coupled with increased demands from institutions on faculty time and output, are key concerns (Lloyd, Byrne, \& McCoy, 2012).

It should be noted that although the challenges are clearly explicated, the focus, in the end, is on student needs and their learning outcomes. The emphasis then is on those methodologies employed to reach learners successfully online.

Another argument within distance education has to do with the instructor him or herself, as if some professors are more equipped to teach online than others regarding this concept of individualized learning. Robert Ubell (2016), vice dean for online learning at New York University's Tandon School of Engineering and author of the book Going Online: Reflections on Digital Education, denies that premise. Instead, he asserts that good faculty members succeed in both face-to-face and online environments, particularly because they are focused on individual learners and not only who they are but also what they need to succeed as people (Ubell, 2016).

Again, the quality of online learning is tied back to an understanding of the students and an instructor's ability to meet those specific learners' needs. Although universities and educators may want to focus on technology, training, content rigor, or other issues, some academics assert that teaching is about knowing where students are and where instructors can help them be next, in regard to meaningful cognitive learning that transforms individually. 


\section{Knowles's Andragogy Regarding Adult Learners}

If online learning's key foundational aspect is the learner him or herself, it makes sense to pivot toward a general notion of who these distance education patrons are before the attempt is made to understand them as separate people. Murry (2017) cites research from the National Center for Education Statistics, where more than one third of college students are over age 25 and one quarter are older than 30. In addition, growth is expected in these older age ranges, as students over the age 25 will grow within the college population by another 23 percent by 2019 (Murray, 2017). This was echoed by Jill Buban, senior director of research and innovation with the Online Learning Consortium, who, in pointing out flaws in the recent Caroline Hoxby study on online learning, noted that since distance learning has begun in earnest, older learners have greatly benefitted by online access to education (Lederman \& Dimeo, 2017).

Using these two pieces of evidence as guides, it is then useful to employ the seminal work of Malcolm Knowles (1990) on the concept of the adult learner. His research showed the desires involved in andragogy - the method and practice of teaching adult learners - as a clear set of expectations and transparent communications; it's the notion the course will not be preloaded from the start, but will change around individual learner's goals. Through an exhaustive study of models, theories, and pedagogies, Knowles (1990) asserted instructors for younger learners should be "concerned with transmitting information and skills" as a contentdriven model, whereas for adults, a process model should be used that provides "procedures and resources for helping learners acquire information and skills" (pp. 102-103). This subtly worded difference is quite radical in practice, as andragogical instructors change their role to be one that facilitates, consults, and advises through the framework of understanding and opportunity for individuals to make meaning for themselves, at the level of their own achievement.

\section{Dick and Carey's Instructional Design Focus on Needs Assessment}

Often, even for adult learners, the learning goals or outcomes for a course are set long before instruction is designed and far before any students are known. Although this is quite useful for building course catalogs and program tracks, it does not address the needs of individual learners, nor does it adhere to many of the tenets of Knowles's andragogy where learners take the lead. Abrami, Bernard, Bures, Borokhovski, \& Tamim (2011) acknowledge that instructional design is a key element to crafting effective online learning, specifically when designing objectives for learners to accomplish. This is where knowledge of instructional design comes into play, and the Dick and Carey Instructional Design Model is one of the more comprehensive methods developed to place emphasis on the knowledge gained about students at the beginning, as well as throughout the learning process. Instructional design, defined as the systematic development of learning that employs theory, has two parts for the learner in this model: the first is a full-bodied, front-end analysis that asks for an in-depth needs and learner assessment before instruction ever begins. According to Dick, Carey, \& Carey (2009), this needs assessment is essential to the total design of instruction for a number of reasons, including the fact that meaningless learning activities waste not only time and resources but also can be demoralizing and counterproductive for the learners themselves. The Dick and Carey model works to address this lack of prior knowledge of student needs for this reason.

When educators understand the learners, the context in which skills or knowledge will be used, and the tools that will be possible within an educational context, the ability to reach students where they are is greatly enhanced. Although some keen instructors can do this 


\section{Making Instant Adjustments in Online Journalism Education: \\ Responding to Continuous Needs Assessments in Asynchronous Courses}

intuitively during the first few days of class, online learning means a literal and philosophical distance, making this intentional step all the more valuable, whether through surveys, student interviews, or research and observations (Dick, Carey, \& Carey, 2009).

The second aspect of this model is a clear acknowledgement that continuous improvement or a sense of concurrent processes is vital because so often "planning, development, implementation, and revision all occur at the same time or in multiple cycles of simultaneous activities" (Dick, Carey, \& Carey, 2009, p. 4). Learning is not a linear process as often as it is a cyclical or recursive one, and this model's awareness of how often a plan goes astray, requires more input, and therefore some revision, is quite applicable and adaptable to an online learning situation.

\section{Methods}

\section{Setting}

This trifold research foundation - focus on the requirements of the students, theories of best practice for adult learners, and needs and learner assessment constructs in instructional design - were the driving factors for studying three online-only, graduate-level courses for high school journalism advisers. The courses were hosted through a public regional university of approximately 7,000 students. When these courses were first taught in the 1990s, the professor who designed them was on the cutting edge of distance education.

Although the courses were groundbreaking at the time, technology has changed, and their resurrection of the asynchronous classes in the summer of 2017 meant complete reinvention. There were 10 total participants in the one-credit hour, graduate-level courses and they were diverse as they came from different states, educational backgrounds, level of advising experience, and journalistic knowledge.

At the beginning and the end of each three-week, online course, students were asked to take a short online survey, using Typeform, to explain their background, expectations, and fears/reactions regarding online learning. All 10 students who participated in each of the three courses (in various configurations) responded to the survey, which was comprised of six new journalism advisers, two experienced advisers (one to five years of experience), and two veteran advisers (five or more years of experience).

The preassessment provided the needs assessment asked for by the Dick and Carey Instructional Design Model. Then, the fact that there was demonstrated change from the pre- to postassessment reflected the individualized learning and emphasis of a clear set of expectations and transparent communication for adult learners. During the pre- and postassessments for online learning, advisers answered the following questions: 
Table 1.

PRE: What do you most hope to gain from this course? POST: Now that this course is complete, what learning outcome was most valuable for you?

Specific lesson plans that can be used next school year

More ideas about various areas of advising Preassessment Postassessment

Framework or structure for a student media course

$\begin{array}{cc}70 \% & 60 \% \\ 60 \% & 70 \% \\ 50 \% & 40 \% \\ 20 \% & 10 \% \\ 0 \% & 50 \%\end{array}$

Table 2.

PRE: What are your concerns, if any, with taking an online journalism-advising course?

POST: Now that the course is over, what were the biggest struggles with taking a journalism-advising course online?

Percentage Percentage Preassessment Postassessment

Clarity of instructions and assignments

Lack of face-to-face interaction with instructor

Time management for online deadlines

Lack of face-to-face interaction with peers

$\begin{array}{cc}40 \% & 0 \% \\ 30 \% & 30 \% \\ 30 \% & 50 \% \\ 10 \% & 30 \%\end{array}$

Percentage Percentage Preassessment Postassessment the best for you, specifically in this online environment?

Readings

$60 \%$

$80 \%$

Discussions

$50 \%$

$40 \%$

Interaction with others

$50 \%$

$10 \%$

Reflection-based assignments

$40 \%$

$70 \%$

Essays or other academic writings

$20 \%$

$20 \%$

Projects

$20 \%$

$60 \%$

Experiential learning
$0 \%$

$0 \%$

Again, it was not that this sample was quantitatively significant in size, but that the process of asking the students, and then being responsive to their answers, altered their perceptions and effectiveness of online learning. 
Making Instant Adjustments in Online Journalism Education:

Responding to Continuous Needs Assessments in Asynchronous Courses

\section{Results}

More specifically, based on the initial data from the preassessment, a number of alterations were made in the courses before they formally began. Because students overwhelmingly desired specific lesson plans that could be used in their classrooms, as in Table 1 , extra assignment sheets were added and artifacts from programs both in the readings and as optional choices. When students identified clarity of instructions and assignments as a concern (see Table 2), explicit learning outcomes were added on the syllabus in each module, with detailed assignment descriptions. Emails were sent once during nearly every module regarding expectations for assignments and level of completion, and then feedback was provided to each student within 24 hours of posting to formatively assess if they were progressing regarding performance. Based on the postassessment in Table 2, clarity was well-addressed overall. Lastly, in Table 3, when students noted that readings and discussions were the way they would learn best, each individual post received a comment in some way, expanded and revised the reading selections based on student feedback on those blogs or posts, and connected students to each other within those responses, in order to propel the desired interaction with others, another component of the responses.

\section{Self-Assessments for Skills and Knowledge}

Although much was gained from those initial pre- and postassessments regarding online learning, there was also a need to understand the adult students' grasp on content, particularly in such a specialized online course. So, a self-assessment regarding perceived strengths and weaknesses regarding journalism advising was administered. From these qualitative findings, the results were coded into three main themes: structure for the courses taught, issues of motivation and working with students, and tools and materials for enhancing programs. To this end, more readings (some which were optional) about various areas of advising were added, particularly those that had advisers speaking to advisers from real, and sometimes harrowing, experiences with student media staffs. Specific examples of syllabi and assignments were also added so students could use them as a starting point for their own programs.

\section{Content Adjustments}

After two initial needs assessments, the courses began, and although they were already built, they were updated constantly throughout each three-week course.

Instructor Reading Alterations. The readings in the course stayed fluid. There was not a textbook, just a varied set of open educational resources, so readings could be added and subtracted and examples could be posted a day before the next module started. By paying attention to blogs and discussions, individual students' needs were clear, and with a small change in the learning management system, adjustments to readings could focus on their needs and goals, while still maintaining core pieces that were foundational to the theme of the module.

Student-led Reading Selections. After the first course, a few students mentioned in postassessments that some readings did not apply to their situation. So, in addition to responsiveness within discussions, the second two courses provided the chance for each student to add one or two readings of his or her own to one module of choice. The effectiveness of this technique was shown when students mentioned the texts others chose in their blogs:

After reviewing the readings in module 5, I felt like there was a ton of valuable information that will help the yearbook be successful. In the reading, "Managing A High 


\section{Making Instant Adjustments in Online Journalism Education: \\ Responding to Continuous Needs Assessments in Asynchronous Courses}

School Yearbook Staff: Photographer" it states, "Managing a high school yearbook staff can be a full-time job in and of itself; show your students the basics of photography and manage your equipment and their time with ease." This is a great point; you are limited to one school year to teach your students the basics of building a yearbook.

This allowed for adult, experienced students to drive the content even more, which supports Knowles's andragogy theory, and more auxiliary readings were taken off the list to accommodate the student-chosen readings. In blogs and discussions, students referred to these peer-selected readings often, as in the above example. The data in Table 2 provide evidence for a readings system that worked for students.

\section{Interactive Discussions}

Along with this monitoring of student needs, the instructor kept note of which learner was interested in what outcomes and then researched and provided resources and responses for those goals through discussion/responses. The time investments seemed to mean a lot to the individual students who often mentioned they would use those specific resources in the coming school year. Also, there was an increase in frequency of similar posts from other students. "I also like that idea of getting into the ethics of journalism right away, helping students understand some of the 'why?' behind what they're doing. There's a good chance you've already seen this TED Talk, but Simon Sinek's thinking on the importance of 'Why?' has helped reframe my teaching philosophy over the past few years," one student posted in response to another. This increase in specific, resource-based interaction made the online course not only more interesting but also more tailored to the needs and goals of other individual students.

After one particular postassessment comment, another structural change was made in the courses. "The discussions weren't much of a discussion. It would have been nice to have assignments that were a little more informal that inspired more $\mathrm{Q}$ and A discourse amongst the advisers." This student comment indicated that not enough cohesion was occurring between student posts, which were, at that point, self-select regarding topic. So, three suggested ideas for responses to that module's readings were inserted, allowing for more commonality among various students' postings.

In the first set of pre- and postassessments, there was some concern about a lack of faceto-face interaction with the instructor, so a few more videos-beyond just an introduction and conclusion multimedia presence - that contained the types of comments or questions posed in a typical classroom setting were added. Through these introduction videos to each module, the instructor shared stories from advising experiences. "To start, I love the ideas talked about in her video on how to be creative with the writing in the yearbook," one student wrote. Particularly in the third course, the videos were more informal and conversational, and there was a clear increase in students referencing what was said in the videos during blog posts.

\section{Summative Assessments Individualized}

Making final, summative projects practical and applicable to individuals was one of the final goals to ensure a recursive, needs-assessment driven online course. At first, there were more academic-style, capstone assignments, as would befit a graduate-level course, but as the pre- and postassessment data was gathered, reflection was ranked as much more valuable for these learners, so they could bring the ideas into their classrooms and newsrooms. Therefore, the summatives were adjusted to include both scholarly and reflective components. The scholarly 
Making Instant Adjustments in Online Journalism Education:

Responding to Continuous Needs Assessments in Asynchronous Courses

pieces were to be built gradually through the responses and discussions on the readings, with citations and references, but the miniprojects and full summative projects allowed for those academic notions to be vetted and applied within the adviser's own context. The key, of course, was that these essays, projects, and artifacts created would be shared, and at the end of each course, all materials were posted for consumption and replication to continue the interaction and practical application that was desired by these students. According to the post-assessment data, the change in both the projects and reflection categories were evidence of a positive reaction.

\section{Conclusion}

This experiment in a recursive, needs-assessment based strategy to provide instant adjustments to an online course was far from easy. In fact, it was quite time-consuming; most online courses take high levels of investment in design at the outset, but once they begin, the intensity lessens. This model was the opposite. The instructor spent at least two to three hours in adjustments and upkeep every day when two of the courses were running concurrently, which did not include grading time. The attempt to differentiate for individual learners and be fully responsive did have limitations. First, 10 students is a small sample size regarding data, so likely more emphasis should be based on the qualitative findings regarding statistical versus anecdotal validity. Also, some student needs did slip through the cracks, and students mentioned those on the postassessment. "You might be more fully able to address the problems faced by instructors of small single-year journalism programs by having some of your optional readings (like the policy manual) come from smaller programs," one student wrote. And, indeed, most were for larger high school journalism programs, which meant that individual need was not met.

However, there were also moments of responsiveness that allowed students to engage in a way they did not expect in distance learning. "Personally, I thought that this course was amazing; thoughtfully conceived; and well-executed," one student asserted. "Not to suck up literally after submitting an assignment, but I just wanted to say that this is one of the best courses I've taken online or otherwise. You have already eased a lot of my worry about this coming year, so thank you for that!" another wrote. Although these types of comments are the cause for elation for any instructor, both of these students, and others, went on to note that it was the clear application to their own interests and programs that meant the most, as one student wrote on a blog post:

Wow, what a great group of readings! Thank you. I have become that teacher when, upon hearing that a PD is planned for what our school calls Professional Learning Mornings (PLMs for short), my brow furrows and I wonder what I will be able to take away from the session and apply to my classroom. Sadly, PLMs often disappoint, leaving feeling frustrated because I don't always feel that I have learned anything. Give me something I can apply and I will try it out the next day. I blather on about this because, Module 5like what I perceive to be a "successful" PD-has given me much with which to ruminate.

Due to the focus on the learner as the heart of the online experience, the notions of Knowles regarding andragogy and the unique traits of the adult learner, as well as the systematic nature of needs assessment exemplified in the Dick and Carey Instructional Design Model, these courses were able to accomplish the task of being responsive to learners. For that and the quality educational experience they gained, both time and effort were keenly invested. 


\section{References}

Abrami, P. C., Bernard, R. M., Bures, E. M., Borokhovski, E., \& Tamim, R. M. (2011). Interaction in distance education and online learning: Using evidence and theory to improve practice. Journal of Computer Higher Education, 23, 82-103.

Dick, W., Carey, L., \& Carey, J. O. (2009). The systematic design of instruction (7th ed.). Pearson.

Knowles, M. (1990). The adult learner: A neglected species (4th ed.). Gulf Publishing.

Lederman, D., \& Dimeo, J. (2017, March 1). A range of experts weigh in on a scholar's controversial new study of online learning. Inside Higher Ed.

https://www.insidehighered.com/digital-learning/article/2017/03/01/range-experts-weighscholars-controversial-new-study-online

Lloyd, S. A., Byrne, M. M., \& McCoy, T. S. (2012, March). Faculty-perceived barriers of online education. MERLOT Journal of Online Learning and Teaching, 8(1), 1-12.

Mayer, R. (2019). Thirty years of research on online learning. Applied Cognitive Psychology, 33, 152-159. https://doi.org/10.1002/acp.3482

Murray, J. (2017, February 21). Has the time come for personalized higher education? Brookings Institution. https://www.brookings.edu/blog/brown-centerchalkboard/2017/02/21/has-the-time-come-for-personalized-higher-education/

Ubell, R. (2016, December 13). Advice for faculty members about overcoming resistance to teaching online. Insider High Ed.

https://www.insidehighered.com/advice/2016/12/13/advice-faculty-members-aboutovercoming-resistance-teaching-online-essay 